\title{
IMAGINAÇÃO E EXPERIÊNCIA: NATUREZA E PAISAGEM EM FRONTEIRAS AMAZÔNICAS ${ }^{1}$
}

\author{
Márcia Regina Capelari Naxara²
}

\begin{abstract}
RESUMO
Tomo em consideração, para aproximações ao espaço amazônico no início do século XX, dois livros de Gastão Cruls (1888-1959) que têm partes da região por centralidade: o romance A Amazônia misteriosa (1925), ficção com reconhecida inspiração em H.G. Wells, e o relato de viagem A Amazônia que eu vi (1930), narrativa da Campanha de Inspeção de Fronteiras com a Guiana Holandesa comandada pelo General Rondon. Textos que incorporam vasta bibliografia sobre a região - espaços, gentes, paisagens - dados a conhecer privilegiadamente pela palavra e seu poder constitutivo de imagens, e pelo desejo da experiência da viagem no objetivo de confrontar o aprendido de segunda mão e concebido na mente com o itinerário realizado e vivenciado in loco.
\end{abstract}

Palavras-chave: Amazônia. Relatos de viagem. Experiência. Imaginação.

\section{IMAGINATION AND EXPERIENCE: NATURE AND LANDSCAPE ON AMAZONIAN BORDERS}

\begin{abstract}
For approximations to the Amazonian space in the early twentieth century, I consider two books by Gastão Cruls (1888-1959) that have parts of the region as their central theme: the novel A Amazônia misteriosa (The mysterious Amazon - 1925), fiction with H.G. Wells recognized inspiration, and the travel report A Amazônia que eu vi (The Amazon that I saw - 1930), a narrative of the Border Inspection Campaign with Dutch Guiana led by General Rondon. Texts that incorporate a vast bibliography on the region - spaces, people, landscapes - made known primarily through words and their power to create images, and through the desire for the experience of traveling in order to confront what was learned secondhand and conceived in the mind with the itinerary accomplished and experienced in loco.
\end{abstract}

Keywords: Amazon. Travel reports. Experience. Imagination.

Data de submissão: 11.06 .2021

Data de aprovação: 16.08 .2021

\section{INTRODUÇÃO}

Los fundamentos que ay para assegurar la Província de las Amazonas en este rio, son tantos y tan fuertes que seria faltar à la fée humana el no darles credito.

Padre Cristóbal de Acuña.

Nuevo descubrimiento del Gran Rio de las Amazonas [1641].

(CRULS, 1973a, p. 54)

\footnotetext{
${ }^{1}$ Versão preliminar, com o título "Paisagem e natureza: imaginação e experiência em fronteiras amazônicas", foi apresentada na Mesa "Imaginário e Natureza", no III Seminário Interferências: Literatura e Ciência - Poéticas e Políticas da Natureza, realizado no Instituto de Letras da UFF - Universidade Federal Fluminense, em novembro de 2019.

2 Professora Livre-docente. UNESP - Universidade Estadual Paulista. Pesquisadora CNPq-2. Email: mrnaxara@uol.com.br.
} 
Lendo a A Amazônia que eu vi, o leitor se empolgará da beleza do vale do Cuminá e da imponência da natureza que ele guarda e protege.

Terá feito ideia perfeita do arrojo da Expedição e da decisão dos expedicionários de realizá-la a todo custo.

Cândido M. S. Rondon Carta ao Dr. Gastão Cruls - Rio (CRULS, 1973b, p. xxxiii)

O fascínio da floresta e das terras interiores do continente sul-americano esteve presente, desde o princípio, no contato entre mundos: o velho e o novo. No caso do Brasil, com colonização de forte litoraneidade desde os "descobrimentos", o desconhecido e o mistério alimentaram a imaginação com relação ao conjunto das terras que o conformam. Território continuamente alargado pelo avanço por sobre as fronteiras iniciais - para além de Tordesilhas -, até a constituição do mapa e do traçado em que nos reconhecemos hoje. Espaços e fronteiras dados a conhecer, privilegiadamente, pela palavra e pelo desenho/imagem, por um conhecimento que se desdobra a partir de leituras que ensejam o desejo contínuo da experiência da viagem - do ver, do ouvir, do contar e do representar. Viagens que descortinavam o reconhecimento de gentes e paisagens, ou seja, possibilitavam aproximar e confrontar o conhecido de segunda mão, concebido na mente, em geral longamente acalentado por leituras pregressas, com o itinerário realizado e vivenciado in loco.

Escritos de diversas ordens, produzidos por romancistas e homens de ciência que se fizeram viajantes e aventureiros, buscando documentar literariamente o real e a experiência vivida, alçando a imaginação para a produção fictícia do que se apresentava como realidade. Espaços narrados em diferentes formas de apreensão e também diferentes formas de ocupação do mundo na modernidade e da sua narrativa literária como viagem. Medo e fascínio; aproximação e repulsão; arrebatamento e êxtase; deslumbramento e encanto são, entre outras, expressões dos sentimentos que a leitura dos textos de viagem - realizadas, lidas e/ou imaginadas - pode proporcionar.

Detenho-me em dois textos de Gastão Cruls (1888-1959). Textos lidos com a presença ausente e constante de Euclides da Cunha (1866-1909) e Alberto Rangel (1871-1945). ${ }^{3}$ Aproximadamente contemporâneos os três, todos profundamente marcados pela antinomia "civilização" e "barbárie", tendo produzido escritos que associam imaginários longamente idealizados ao conhecimento que veio da experiência dos caminhos percorridos, que se mesclam em seus textos, por sua vez também ancorados em leituras mitológicas e folclóricas sobre a natureza amazônica e suas populações. Euclides e Rangel, ambos com formação na Escola Militar, de que se desligaram, tinham interesses aproximados pelo Brasil, seus espaços e sua história. Em se tratando da Amazônia, Euclides chefiou a Comissão Brasileira de Reconhecimento do Alto Purus (1904-1905) na ocasião em que se definiam fronteiras com o Peru e a Bolívia, marcadas pelos embates entre caucheiros e seringueiros; Rangel foi Diretor Geral de Terras e Colonização na Amazônia (1901-1904) e Secretário-Geral do Governo do Estado do Amazonas (1904-1905), antes da sua atuação diplomática na Europa e seu primeiro livro de contos, Inferno verde, de 1909, tem prefácio largamente conhecido de Euclides da Cunha. No conjunto, os escritos de ambos sobre a região aproximam o leitor com relação às formas de ocupação e modos de vida em meio à floresta tropical - inferno, deserto, sertão - de vivências conflituosas e disputa entre gentes, rios e florestas, à medida em que buscaram documentar literariamente o real, alçando a imaginação para, pela narração, construir diferentes espaços amazônicos, em meio ao espaço maior, a Amazônia.

\footnotetext{
${ }^{3}$ De Euclides da Cunha, parte dos textos datados do final do século XIX e início do XX, reunidos em Contrastes e confrontos (1975) e À margem da história [1909]; de Rangel, Inferno verde (1909) e Sombras n'Água (1913).
} 
Cruls veio a conhecer a Amazônia, de perto, somente em 1930. Antes, em 1925, escreveu A Amazônia misteriosa, criação literária em que recuperou lendas e memórias referidas às Amazonas e que se perdem no passado dos escritos de Frei Gaspar de Carvajal ao narrar a famosa viagem de Francisco de Orellana (1511-1546) ${ }^{4}$ e da denominação que o rio e a vasta bacia que o conforma veio a alcançar - AMAZONAS / AMAZÔNIA. Em 1930 publicou o relato de viagem A Amazônia que eu vi: Óbidos e Tumucumaque, em texto composto na forma de diário, na ocasião em que acompanhou a Expedição da Inspeção de Fronteiras no setor de limites com a Guiana Holandesa, comandada pelo então General Rondon - "Expedicionários da cordilheira Tumucumaque, seguindo o rio Cuminá e Meridiano de $55^{\circ}$ a $W$ de Greenwich", nas palavras do General (CRULS, 1973b, p. xxxiii), que partiu de Óbidos, em 13 de setembro de 1928. Retornou à Amazônia em 1938 (CRULS, 1973a, Nota da Editora, p. xiii) e, somando com conhecimentos da primeira viagem e outros estudos sobre a região, publicou Hiléia Amazônica: aspectos da flora, fauna, arqueologia e etnografia indígenas, ilustrada em sua primeira edição - príncipe - de 1944, com 48 pranchas aquareladas em "tiragem bastante restrita e de grande luxo", tendo em vista a rica e policrômica iconografia. ${ }^{5}$ As duas edições seguintes, uma do mesmo ano (1944) e outra, de 1958, financeiramente mais acessíveis, foram impressas em tamanho usual, com as 48 reproduções de aquarelas em preto e branco. Nas palavras do autor, "volume mais portátil e de preço mais acessível", além de contar com "uma série de acréscimos, como elucidário, bibliografia geral e completo índice remissivo" (CRULS, 1958, p. IX).

Tomados em conjunto são textos que possibilitam acompanhar percursos e itinerários que alimentaram longamente a imaginação histórica e literária, bem como a formulação de alguns dos quadros paisagísticos e mentais que vieram a se formar sobre a vasta região amazônica, responsáveis pela construção de aspectos duráveis da memória coletiva que sobre ela se consolidou. Exploram sensibilidades vazadas pelos escritos e imagens produzidos ao longo do tempo, voltados para as imensas áreas que foram dando forma ao desenho interior do mapa que hoje delineia o país/pátria, e que são, até hoje, marcadas de modo indelével pela admiração da natureza e pelo lamento quanto às formas deletérias de sua ocupação pelos movimentos que buscam a preservação e o respeito, tanto da natureza como dos povos que nela vivem. Textos que possibilitam, também, aproximações que resultam do ver, ouvir e sentir: o rio, a floresta, os campos, as cachoeiras, ao acompanhar os percalços dos caminhos, somando a imaginação que antecede a viagem às observações in loco, de que resultam textos engajados no reconhecimento do espaço percorrido e do esforço coletivo que propicia a empreitada. Viagens cujos relatos ampliam o conhecimento ao narrar as dificuldades enfrentadas; em que, em geral, a partir dos personagens centrais, protagonistas que comandam a narrativa entremostram, como é o caso de Cruls, aqueles que tornam o caminhar possível: pode-se colocar ênfase no "descalços" para a forma como seguem os carregadores e remeiros, que se fazem também pescadores, caçadores e cozinheiros, que cuidam e calafetam as embarcações (por vezes construindo novas) de modo a viabilizar a viagem programada em seus objetivos. Nem sempre e, seguramente não todos, são nomeados - grande parte, invisivelmente, torna o empreendimento possível. Relatos que, além do contato com o desconhecido, colocam ao leitor, de modo "vivo", as dificuldades enfrentadas: os inúmeros perigos, o excesso ou a falta de

\footnotetext{
${ }^{4} \mathrm{O}$ relato de Frei Gaspar de Carvajal, Relatório do novo descobrimento do famoso rio grande descoberto pelo capitão Francisco de Orellana, da viagem realizada entre 1541 e 1542, acentua, em especial, a fome e o medo da fome em meio à viagem pelo desconhecido, a partir do ponto de não retorno com relação ao anteriormente programado, além das relações, ora de paz, ora de conflito, com a numerosa população autóctone que registra ao longo da viagem, em que Orellana vai proclamando a posse em nome de Sua Majestade (CARVAJAL, 1992).

${ }^{5}$ Cabe conferir ênfase aos artistas que produziram as 48 aquarelas que constam da publicação - Hilda Veloso, Armando Pacheco e Georges Julien Simoni -, além dos Culs-de-lampe de Luís Jardim, ao final de cada capítulo (CRULS, 1958, página de rosto).
} 
correntezas, as longas caminhadas por rios e veredas desconhecidas - carregando as embarcações e as "tralhas" por terra, quando necessário para vencer as cachoeiras e, na sequência, retornar ao rio. No caminho, os contatos com as populações locais, caboclos e indígenas, mais ou menos amistosos e/ou receptivos aos estranhos/estrangeiros.

$$
* * *
$$

A Amazônia misteriosa e A Amazônia que eu vi: Óbidos - Tumucumaque. Dois livros; duas criações literárias em narrativas que constituem e elaboram espaços: no primeiro caso, primeiro romance do autor, viagem imaginária que, além de remeter para escritos anteriores de viajantes que passaram pela região, aponta inspiração assumida por Cruls de A Ilha do Dr. Moreau, de H. G. Wells (1896); no segundo, narrativa que dá a conhecer o espaço percorrido no compasso mesmo da sua constituição e conhecimento, ao menos em parte, uma vez que a expedição, comandada por Rondon, tinha por finalidade explorar as fronteiras entre o Brasil e a Guiana Francesa e Suriname, atravessando com dificuldades territórios ainda por demarcar e não explorados pela "civilização".

$* * *$

\section{AMAZÔNIA: ROMANCE E FANTASIA}

Em A Amazônia misteriosa Gastão Cruls buscou, de início, acompanhar o modelo dos relatos de viagem - localizando dia e mês da segunda década do século XX - "17-XII-191...", como parte de "um dia monótono e cansativo", ao indicar os caminhos ermos que iam sendo percorridos e a possibilidade de "encontro com os índios... Creio já haver mais de um mês que tivemos o último vestígio do civilizado" (CRULS, 1973a, p. 3). Segue elaborando o diário da expedição em seus percalços para, na sequência, no Cap. II, que tem o significativo nome "Perdidos...", dar início à aventura do protagonista/doutor, que se desgarra da expedição e se perde na mata na companhia de dois caboclos - Pacatuba, personagem presente na narrativa desde o início, e Piauí. Os três se embrenham na floresta e, nas palavras do autor, perdem-se entre as "sumaumeiras gigantescas, tocaris hercúleos, majestosos cedros" por entre a "legião sem fim dos outros vegetais", por entre os ruídos de macacos, beija-flores e outros pássaros que, com a chegada da noite vão sendo trocados pelo "rechino de algumas cigarras e a coaxação dos primeiros sapos" (CRULS, 1973a, p. 20). Registra, ainda, o temor da possibilidade da presença de "bugres": "O senhor nem imagina do que essa gente é capaz", afirma Pacatuba (CRULS, 1973a, p. 22). O espaço narrado, imaginariamente criado pelo autor, constitui visão da Amazônia que, sem dúvida, é devedora dos relatos de viajantes e naturalistas, incluindo "nordestinos migrados e caboclos da região", em interessantes interlocuções que aproximam e colocam em contato os diferentes costumes, crenças e visões de mundo, além de constituir recurso que aproxima o imagético ao documental (PAIVA, 2019).

No perder-se na floresta e no deambular em meio ao desconhecido, vão sendo recuperadas na narrativa as histórias e lendas longamente acalentadas sobre o contato entre brancos e indígenas que preenchem o conhecimento sobre a América e o Brasil de modo geral e sobre a Amazônia em particular. Repentinamente são abordados por um grupo armado. $\mathrm{O}$ suposto interesse dos indígenas por objetos para eles inusitados, serve de pretexto ao narrador para lembrar o ensinamento de Rondon quanto a não utilizar armas.

Quando dei acordo de mim, estava mais próximo do córrego, dizendo coisas aos selvagens, mais por gestos do que por palavras, e mostrando-lhes o meu relógio e corrente de ouro e um espelhinho de bolso, os únicos objetos que tinha sobre mim com probabilidades de interessa-los... (CRULS, 1973a, p. 24). 
Narrativa que prepara a súbita surpresa de, depois de "alguns minutos de ansiosa expectativa", ter diante de si uma "bela figura de homem", acompanhado de outros seis. Sem argumentar, puseram-se em marcha, acompanhando os indígenas, com quem embarcaram na manhã seguinte, sem conhecer o destino que teriam e perdendo a esperança de retornar ao acampamento. O autor dá asas à fantasia, considerando estar adentrando a "Amazônia fantástica e misteriosa em que cada imaginação prefigura o Eldorado" (CRULS, 1973a, p. 30). Predição que vai sendo confirmada no caminho por onde foram guiados quando têm a atenção chamada para "certo amuleto que pendia do pescoço de muitos deles": o muiraquitã, a "célebre pedraverde que fora o distintivo das Amazonas de Orellana [...] e que os índios, para explicar-lhes a procedência, diziam provir do "país das mulheres sem marido"" (CRULS, 1973a, p. 32).

Dessa guarda são passados para uma outra escolta, de grupo indígena visto pelo narrador, por seus traços físicos, como "de raça mais pura" (CRULS, 1973a, p. 32). Da natureza para a fantasia vão sendo costurados, na narrativa, muitos dos elementos significativos de fábulas disseminadas sobre as terras americanas e seus segredos. Os homens, diz o narrador, acompanham incansavelmente a caminhada, com grande probabilidade devido a uns "confeitos de tapioca que os índios chupavam constantemente" e que lhes foram oferecidos de vez em quando. Confeitos que, informa, "continham ipadu, que outra coisa não é senão a mesma coca de que tanto usavam os Incas como excitante e alimento de poupança durante as suas longas marchas" (CRULS, 1973a, p. 39). No trajeto um deles, Piauí, tomado por febres, perde-se e "desaparece" no espaço imenso e fechado da floresta e ao final da caminhada, o narrador e Pacatuba chegam "em pleno coração da selva, na mais recôndita paragem", a uma muralha de pedra que dá acesso a uma cidade em miniatura, formada por ruas largas, casas amplas e bemacabadas: a terra das lendárias Amazonas, a quem são entregues: "Dir-se-ia a visão de um sonho, tal o espanto do que os meus olhos viam" (CRULS, 1973a, p. 43).

Central à história, tem início a narrativa do encontro dos dois homens - narrador e Pacatuba - com as famosas Amazonas e com o estranho personagem denominado "alemão". É ele quem informa aos forasteiros o fato de estarem entre as "autênticas" Amazonas, compondo a cena de mistério, entre lenda e realidade. ${ }^{6}$

\begin{abstract}
- Pois é o que lhe digo. Estamos entre as autênticas Amazonas, a célebre tribo das mulheres guerreiras que, há quase quatro séculos, foram vistas pela primeira e única vez, por Orellana e seus companheiros. Fique certo que o meu espanto não foi menor que o seu, quando me convenci dessa descoberta e tive de entroncar estas índias que nos rodeiam, àquelas mesmas que, armadas de arcos e flechas, na foz do Jamundá, atacaram os primeiros exploradores do rio-mar. E como proceder de outro modo, se todos os dados vêm em abono dessa afirmação e fazem de uma simples lenda a mais palpável realidade? (CRULS, 1973a, p. 54).
\end{abstract}

Pode-se reconhecer o engenho do autor ao recuperar, dos relatos da viagem de Orellana, as lendas ao longo do tempo alimentadas sobre a região em seu recontar e re-criar a história,

\footnotetext{
${ }^{6}$ A narrativa de Karl Friedrich Philipp von Martius, Frey Apollonio: um romance do Brasil, guarda aproximações com A Amazonia misteriosa de Gastão Cruls. O enredo tem como cenário a região do Rio Japurá, nos limites entre o Brasil com a atual Colômbia e se desenvolve por meio dos debates triangulados entre o personagem (autorreferenciado) Hartoman, com o jesuíta Frey Apollonio e Riccardo, italiano há muito radicado no Brasil, tendo como um de seus pontos centrais as representações das populações locais, autóctones, como decadentes e reconhecendo somente em parte delas a possibilidade de desenvolvimento futuro, pela ancestralidade heroica Inca. O manuscrito, datado de 1831 e assinado pelo anagrama do autor, Suitram, permaneceu inédito até 1967, ao ser descoberto na Biblioteca da Baviera por Erwin Theodor, que o traduziu para o português, com publicação simultânea na Alemanha (Frey Apollonio: ein roman aus Brasilien. Verlag) e no Brasil (Brasiliense), em 1992 (NAXARA, 2004, p. 251-258; LISBOA, 2008). Cabe colocar atenção aos nomes dos protagonistas: Hartoman, no caso de Martius; Hartmann, no caso de Cruls - e ao significado de "Hart" como "homem forte, valente".
} 
apresentando ao leitor a intrigante figura, em plena selva, do Alemão ou Dr. Hartmann, construído como personagem bizarro, por marcar presença em uma terra que, em princípio, pela lenda, seria habitada apenas por mulheres. É ele quem, no decorrer da narrativa, recupera a existência histórica das mulheres guerreiras, afirmando estarem efetivamente entre elas, as Amazonas do Reino das Pedras Verdes, as únicas fabricantes de muiraquitãs (CRULS, 1973a, p. 58). Suas ancestrais teriam emigrado do Império Inca, única forma de explicar o seu "grau de civilização", ainda que fosse difícil pensar a "razão desse êxodo tão esdrúxulo, no qual somente indivíduos do sexo feminino se expatriaram" (CRULS, 1973a, p. 59) e onde, em períodos certos, indígenas do sexo masculino eram recebidos para a realização de cerimonial de acasalamento, com a posterior sobrevida somente das crianças de sexo feminino.

Tornando-se uma espécie de prisioneiros - narrador e Pacatuba - passam a vivenciar uma série de estranhamentos ao adentrar à cultura daquele lugar - uma cidade em meio à selva - reconhecido como das Amazonas, lideradas e sob a autoridade da rainha Coia, em seus costumes e ritos peculiares como preservar a virgindade e o acasalamento com os Guacaris, além da excêntrica presença do alemão - Sr. Hartmann - e sua esposa francesa, Rosina, por quem o personagem narrador veio a se apaixonar, e da jovem Malila, indígena que havia aprendido francês, muito próxima a Rosina, que "cuidava" dos forasteiros.

Ao buscar reunir o amplo imaginário que cercava e cerca a região, o personagem narrador, além do ipadu, consumido na viagem para garantir a marcha, vem a conhecer o aiquec ${ }^{7}$ que lhe é dado sem que soubesse, induzindo-o à ilusão e ao sonho ou transe, em que encantado, se visualiza ao lado de uma "figura estranha e intimidante" pelo porte e aparato da vestimenta, ao lado de quem percorre, como que num "extenso vôo por espaços ilimitados e regiões completamente desconhecidas" a antiga Tenochtitlan, que lhe é apresentada em sua magnificência. Ao caminhar, admirando a cidade e ouvindo o interlocutor, abruptamente percebe ter por guia e estar diante do próprio "Ataualpa, o último imperador dos Incas", que numa "nova impressão de vôo" passa a lhe apresentar Cusco, "percintada pelos contrafortes da cordilheira", com o Templo do Sol destacando-se na paisagem - Império de onde teriam partido as Amazonas, ancestrais daquelas que então conhecia. Talvez ponto alto do romance, $O$ Inca (Cap. VII), concentra elementos da ampla bibliografia lendária, encantada e sem veracidade histórica sobre a região (CRULS, 1973a, p. 79-88).

Acompanhando traço significativo na obra de Cruls, que tinha formação em medicina, aparece o elemento misterioso e expressionista, macabro e trágico, central ao romance, que vai sendo desvendado pela curiosidade do narrador: o alemão, Dr. Hartmann, encontrava-se na Amazônia envolvido com experimentos "secretos", realizados em espaços interditados aos visitantes, que incluíam cruzamentos entre humanos e animais, utilizando indígenas como cobaias. A primeira visão do personagem soma elementos do gênero de ficção científica e, como assinalado, guarda aproximação à Ilha do Dr. Moreau de Wells.

\begin{abstract}
Macaco? Preguiça? E atentei mais para o ser estranho que se rojava no chão com movimentos muito lerdos e hesitantes. Não! Era uma criança! Aquelas formas não enganavam e eram bem humanas. Mas então, seria um monstro? Perplexo, a fazer-me mil perguntas os meus olhos não se despregavam mais daquele quadro, visão horrífica e atraente, que a um só tempo despertava sentimentos de piedade, revolta e nojo. E a criancinha continuava a mover-se, espapaçada de ventre, o corpo languinhento e mole, a cabeça bamboante fuçando a palha. [...] Pelo tamanho, devia ser um indiozinho de dois a três anos. (CRULS, 1973a, p. 99).
\end{abstract}

Tratava-se de uma criança - figuração entre o real e o mito, ser antropozoomórfico - a quem o Dr. Hartmann, que contava com um ajudante, misterioso e nunca apresentado ao leitor, havia tirado como experimento a tireoide e o timo nos primeiros dias de vida. O segundo

\footnotetext{
${ }^{7}$ Palavra não dicionarizada; similar à ayahuasca (Psychotria viridis) em seu poder alucinógeno.
} 
espanto veio da informação do engendramento do filho de uma índia com um cuatá - orgulho do cientista. No caso, o enxerto duplo de ovários de macaca cuatá numa índia sexagenária que, pelo procedimento, foi rejuvenescida, dando à luz um hominídeo. Relata, ainda, outros experimentos com animais, como uma descendência bizarra "da cutia com a preguiça, do macaco-prego com o tamanduaí, do peixe-boi com a anta “... além de aves de toda espécie, promovendo uma "verdadeira síntese das espécies" (CRULS, 1973a, p. 118-120). Experimentos que significariam uma busca pela alteração da ordem da/na natureza, imaginário primordial sobre a Amazônia, num sentido da sua dominação crescente, ou mesmo da sua alteração, como se seu "espaço onde a natureza prepondera, [...] alheada do mundo civilizado europeu" pudesse ser convertido num "ambiente permissivo para um livre exercício de experimentos científicos, condenados em sociedades mais civilizadas" (PAIVA, 2019, p. 263).

A narrativa caminha para uma resolução quando, ao perceberem-se prisioneiros, tem início a fuga em busca da liberdade. Pacatuba, o narrador e Rosina (Malila é convidada, mas não os acompanha), dão início ao plano, até serem surpreendidos por silvícolas:

\begin{abstract}
De súbito, algumas flechas assobiaram no ar e vieram chofrar a água bem junto da nossa canoa. [...] Rosina, com o susto, pusera-se de pé, mas eu só percebi a extensão da nossa desgraça depois que ela, dando um grito agudo, já ia arrastada pela correnteza.

- Ela foi ferida! - avisou-me o Pacatuba. E antes que eu me lançasse n'água, já ele nadava com afoiteza e ia em sua direção. [...] Rosina, que sabia nadar, lutava contra a força das águas e parecia visar uma ilhota próxima (CRULS, 1973a, p. 161-162).
\end{abstract}

Em vão buscaram resgatá-la ao rio. O trágico e romântico final fecha o romance: "Foram as piranhas, seu doutor! A flechada talvez não fosse nada, mas isso é um bicho que não pode ver sangue" (CRULS, 1973a, p. 162).

\title{
2 AMAZÔNIA: VIAGEM, CAMINHOS, PRESENÇA
}

Agripino Grieco, ao comentar A Amazônia que eu vi, chama a atenção para que, nele, Gastão Cruls, deixa de ser o "ficcionista dos casos estranhos", para aparecer como o filho do cientista Luís Cruls, escrevendo, "não somente para escrever bonito, mas para transmitir algo de útil", fazendo-nos ver, "neste roteiro de Óbidos-Tumucumaque, uma Amazônia sem assombramentos, bem mais prosaica que a do seu romance sobre o reino das mulheres guerreiras, sobre os muiraquitãs e o sonho do império dos incas" (GRIECO, In: CRULS, 1973b, $1^{\mathrm{a}}$ orelha).

Roquette-Pinto, no prefácio, anunciando a colaboração do autor para a "cultura brasiliana", afirma que o que o leitor irá encontrar:

\footnotetext{
é mais do que a Amazônia que Gastão Cruls viu; é a Amazônia que ele nos faz ver, [...] sem tropos nem lantejoulas. As coisas que ali têm brilho, brilham aqui por si mesmas; as sombras surgem na composição das telas com a intensidade que tinham no modelo, sem excessos da palheta do artista, que sabe trabalhar as tintas com mão de mestre (ROQUETTE-PINTO, 1973b, p. xxxvi).
}

A viagem tem início com a saída de Óbidos, a 13 de setembro de 1928, navegando pelo Rio Amazonas até o Trombetas, de onde se entra para o Rio Cuminá (ou Erepecuru). Os rios são onipresentes como realidade tangível e caminho rumo ao Tumucumaque. ${ }^{8}$ A narrativa busca desenhar o cenário pela descrição dos detalhes e suas diferentes características: flora, fauna,

\footnotetext{
${ }^{8}$ O Parque Nacional Montanhas do Tumucumaque foi criado em 2002 como unidade de conservação e proteção da natureza - maior parque nacional do Brasil e em florestas tropicais do planeta, está localizado nos estados do Amapá e do Pará, limitando-se ao norte com a Guiana Francesa e com a República do Suriname.
} 
condições de navegabilidade - espaço e paisagem - acompanhada do levantamento cartográfico, que mapeava os caminhos percorridos. Há preocupação, também, com o levantamento e estudo das populações, além das pesquisas de caráter arqueológico que, no rio Trombetas, mostram resquícios de antigas civilizações, possibilitando a Cruls assinalar que não deviam "andar longe do Reino das Amazonas, pois foi à foz desse último rio que as lendárias guerreiras atacaram a Orellana e os de sua comitiva: 'Aqui dimos de golpe en la buena tierra y señorio de las Amazonas "', nas palavras de Frei Gaspar de Carvajal (CRULS, 1973b, p. 6). A 19 de setembro, pela primeira vez, Cruls coloca os pés, efetivamente, na floresta amazônica e, ao caminhar, registra o quanto a "mata é portentosa e só por uma ou outra clareira o sol consegue vencer a grenha hirsuta e verde das frondes que se entretecem no alto", os troncos das castanheiras erguem-se em colunas majestosas e pétalas coloridas no chão denunciam que as "árvores andam a florir lá por cima" (CRULS, 1973b, p. 19).

Figura 1. Planta do Rio Cuminá

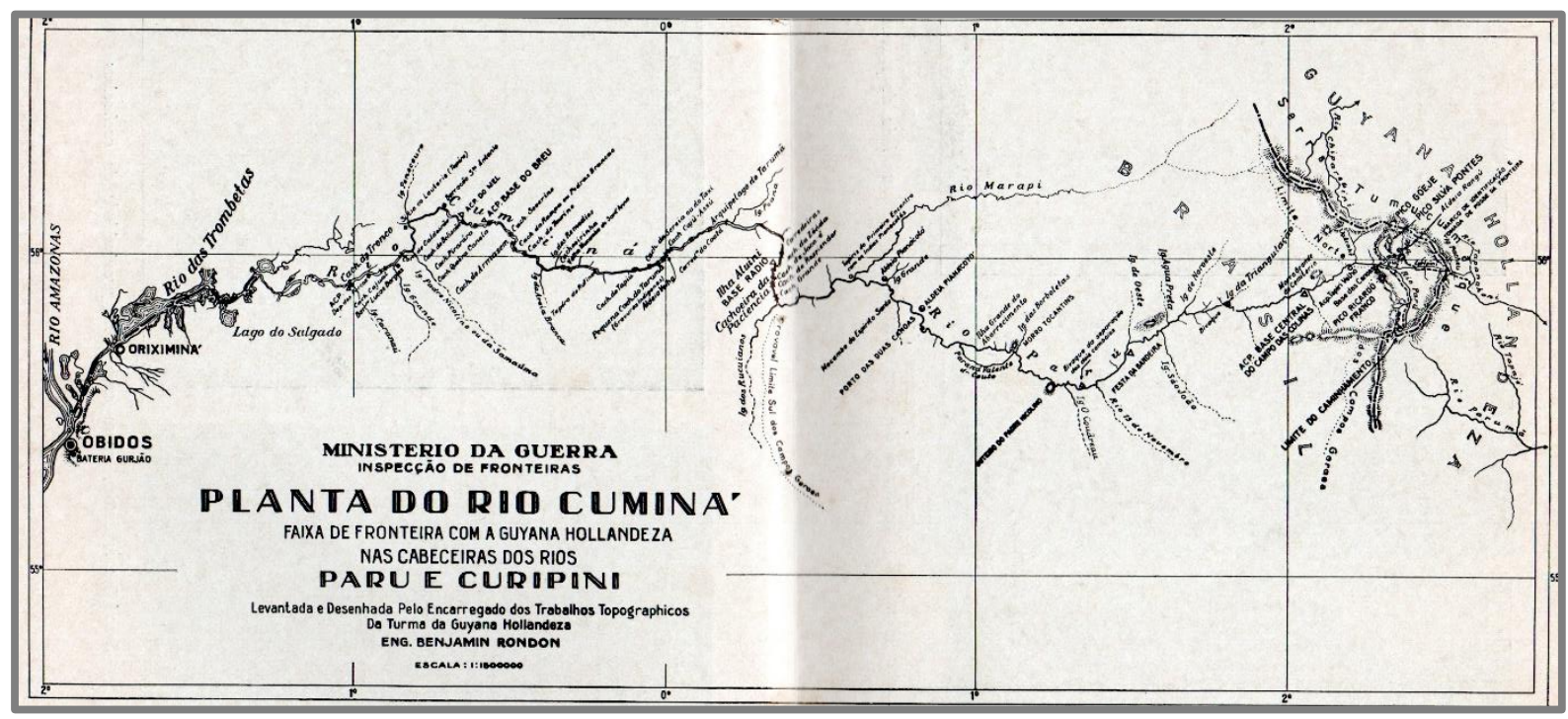

Fonte: Eng. Benjamin Rondon. Planta do Rio Cuminá - Faixa de fronteira com a Guyana Hollandeza nas cabeceiras dos rios Paru e Curipini. Escala 1:1500000 (CRULS, 1973b)

O comando da expedição, como já adiantado de início, é do então General Cândido Rondon, acompanhado de homens formados em diferentes especialidades (etnografia, cartografia, botânica, zoologia), ${ }^{9}$ de modo que a Expedição contava com número significativo de homens de ciência, e, na sua maior parte, com a presença de homens anônimos - Trindade, Galdino, Manuel, João, Braulino, ... - que, como assinalado, muitas vezes enfrentavam o caminho descalços, no duro trabalho de carregadores, remeiros, cozinheiros, caçadores, pescadores, ou seja, tudo que se fizesse necessário. Em trecho difícil do caminho Cruls assinala que

A barba-de-bode, ciperácea de rizoma duro e cerdoso, esponta agressivamente da terra e torna as marchas muito penosas, mormente para aqueles que andam descalços, como

\footnotetext{
${ }^{9}$ Em nota Cruls assinala a participação do Dr. Benjamin Rondon, encarregado do serviço telegráfico; do Major Luís Tomás Reis, incumbido do serviço cinematográfico; do Prof. Alberto José de Sampaio, chefe da seção de Botânica do Museu Nacional; do $1^{\circ}$ Tenente-Médico Dr. José Carlos Gertum; do Dr. João Barbosa de Faria, encarregado do serviço etnográfico; do Major Polidoro J. Barbosa, chefe da turma, encarregado dos serviços astronômico e topográfico (CRULS, 1973b, p. 9, 12, 15, 16, 20).
} 
a maioria dos nossos homens, que têm por isso os pés constantemente feridos (CRULS, 1973b, p. 117).

Os conhecimentos e as dificuldades interpostas vão sendo somados ao longo da narrativa. Ao já registrado acrescentam-se novos pela nomeação de rios e acidentes geográficos "descobertos" no caminho, em especial quando a expedição avança para terras antes não visitadas, ou seja, desconhecidas ao homem civilizado. Cruls cita viajantes anteriores, com destaque para o Padre Nicolino, primeiro explorador do Rio Cuminá, ainda que resguarde a referência ao botânico Richard Spruce, que teria atingido somente a "cachoeira do Tronco", e um "certo Tomás Antônio D’Aquino", citado em 1862, pelo então presidente do Pará, em relatório à Assembleia Legislativa. O Padre Nicolino, subiu o Cuminá por três vezes, em 1876, 1877 e 1878, buscando avaliar a introdução de atividade pastoril na região, tendo falecido na última viagem (CRULS, 1973b, p. 36-37). Suas iniciativas tiveram sequência, ainda que pouco promissoras, no intento de ligar os Campos Gerais do Cuminá a Óbidos. Na sequência, especificando marco importante na exploração que então se realizava, Cruls menciona Otília Coudreau, a quarta visitante do Cuminá (1900), que havia tomado a si a empreitada da viagem para cumprir contrato anteriormente assinado por seu falecido marido, Henri-Anatole Coudreau, com o governo do Pará (CRULS, 1973b, p. 38). Ao assinalar a passagem pelo ponto alcançado por Coudreau, por quem manifesta admiração, Cruls demarca a linha entre o conhecido e o desconhecido (CRULS, 1973b, p. 108). Ultrapassado o marco, a expedição passava a desbravar terras nunca antes percorridas pelo homem branco.

A possibilidade de contato por rádio com o mundo civilizado diminuía à medida em que a expedição avançava, aumentando a sensação de isolamento e os sentidos com relação às dificuldades materiais. A última antena, que possibilitava as "ondas milagrosas" foi erguida em 26 de setembro (CRULS, 1973b, p. 31):

Nessa antena estão todas as nossas esperanças. Daqui por diante, por ela e só por ela poderemos ter contato com um mundo de que, a pouco e pouco, vamos perdendo todas as amarras. É o único nervo que nos resta, o nervo supletivo não sei de quantas sensibilidades [...].

Os espaços vão sendo constituídos no curso da narração pela perspectiva do olhar e da sensibilidade do autor ao narrar, em especial pelo seu cuidado com o detalhe, pelo registro das atividades e percalços do dia a dia. $\mathrm{O}$ isolamento e a solidão levam a devaneios e memórias interpostos ao texto, ainda que o foco seja e continue sempre sendo a viagem: Cruls traça paralelos com o seu próprio livro anterior, A Amazônia misteriosa, ou com outros autores, leituras, sonhos e lembranças. Em 26 de setembro narra sonho em que teria conhecido e visitado Baudelaire (CRULS, 1973b, p. 27); a Lobato, reserva críticas por seu "americanismo à outrance", em dúbia avaliação quanto à entrada de americanos no Brasil no episódio das negociações para a instalação da Fordlândia, que ocorria naquele momento, comparando-a à entrada de possíveis colonos americanos em relação ao "constante e atravancador aportuguesamento do Sul" (CRULS, 1973b, p. 47) ${ }^{10}$, em observação que revela ambivalências com relação às questões raciais em termos de sua conformação no Brasil.

\footnotetext{
10 "Procurando reconciliação com o meu amigo Monteiro Lobato, no que diz respeito ao seu americanismo à outrance, leio, na tradução que lhe devemos, o Hoje e Amanhã, de Henry Ford. Justamente agora, faz-se grande grita, sobretudo em Belém, contra as concessões de terras, feitas ao milionário americano, às margens do Tapajós. Não sei em que base foram assinados tais contratos, nem tenho em grande simpatia as baforadas de automática que com o nome de civilização nos chegam dos Estados Unidos; mas não vejo como se há de combater uma possível imigração ianque quando, anualmente, continuamos a receber muitos milhares de portugueses, na maioria analfabetos. Que será pior, a problemática americanização do Norte ou o constante e atravancador aportuguesamento do Sul? Por outro lado, a natureza amazônica é de tal modo avassaladora que não me espantarei se, dentro em pouco tempo, loiras girls forem vistas às unhas no manejo do tipiti, enquanto os seus irmãos andem
} 
As referências às populações indígenas aparecem ao longo do texto de modo pontual, registrando a dificuldade de contatos mais diretos, uma vez que os indígenas - ainda que não todos - se mostravam arredios, fugindo às aproximações. Em 8 de novembro, Cruls registra sua presença na zona dos Pianocoto, lembrando que o General havia solicitado que as embarcações avançassem afastadas da dele, para que os indígenas não fossem atemorizados (CRULS, 1973b, p. 80). Passando das onze horas avistou-se uma ubá que cortava o rio e nas margens próximas "vultos correndo de um lado para o outro" ainda que o General, em aproximação, gritasse "Moró! Moró!'” (amigo), ao desembarcar encontraram o acampamento abandonado, "tal como o deixaram os índios, isto é, ainda de foguinho aceso, ..., petrechos de caça e pesca, ubás encalhadas na areia... Infelizmente, só faltava aí o que mais nos interessava e eram os silvícolas" (CRULS, 1973b, p. 81), levando o autor a conclui que não deviam estar muito longe. Tapiris acanhados e modestos, em que encontraram, além de objetos "autóctones", vários artefatos que "traíam o contato com o civilizado: panelas de ferro e ágata, dois terçados, um bauzinho de folha e até um prato de boa faiança, com ornamentação a duas cores, possivelmente de origem holandesa", além de uma "bacia de barro contendo massa de mandioca, uma cuia com pimentas frescas e um cacho de bananas"; as ubás, longas e esguias, "feitas de uma casca inteiriça de jatobá, que se arremata em ponta, tanto na proa como na popa" (CRULS, 1973b, p. 82). Na sequência da viagem aparecem, continuamente, vestígios de passagem de índios que o autor, ao longo do texto, mostra evitarem o contato, cautelosamente procurado por Rondon. Quase como contraposição ao relato, vários registros fotográficos capturam Rondon e membros da equipe com indígenas, assinalando proximidade, em especial com os Pianocoto e Tiriô, presentes em várias das fotografias que abrem o volume, assim como em outras pertencentes ao acervo do Museu Histórico do Exército. ${ }^{11}$

A narrativa prossegue indicando que, dias depois, foi estabelecido contato com alguns poucos indígenas: "três homens e uma mulher velha", que resguardavam os demais membros da tribo. A impressão do autor é positiva: "terreno bem roçado", "árvores frutíferas e outras plantas cultivadas". Distribuíram presentes e, em troca, receberam "comezainas":

\begin{abstract}
Achei curiosíssima a maneira como eles falam, sempre muito apressadamente e emitindo sílabas bem escandidas. Essa linguagem picadinha, reunida à fixidez das suas fisionomias, ainda lhes imprime maior caráter ao tipo francamente asiático. Aliás, todos eles pareciam extremamente nervosos com a nossa presença e talvez não os víssemos tais como se apresentam na realidade (CRULS, 1973b, p. 87).
\end{abstract}

Ao final, afirma que deixaram os Pianocoto "radiantes" com as "dádivas: muitos metros de chitão vermelho para futuros rabos, machados, facões, enfiados de contas, caixas de fósforos, anzóis, tesouras", retornando com oferendas: "cachos de banana, mamões, toletes de cana e dois cestinhos contendo farinha de mandioca", listados com a curiosa observação, de que a índia partia o beiju, que tinha mais de um metro de circunferência, com "um empino da própria barriga" (CRULS, 1973b, p. 87). No entanto, em que pese o reconhecimento da diferença, Cruls

\footnotetext{
na salga do pirarucu ou a percorrer as praias de viração. Isto até que o pirarucu indígena passe a figurar como iguaria rara nas latas de qualquer Libby's e seja inventada a chocadeira modelo para ovos de tartaruga." (CRULS, 1973b, p. 27). O projeto que instalou a "Fordlândia" no Pará foi aprovado em 30 de setembro de 1927 e Cruls redige a referência em 1928 (publicado em 1930). O acordo foi encerrado em 24 de dezembro de 1945, sem que as previsões iniciais se realizassem. Cruls conheceu parte do empreendimento quando de sua segunda viagem à Amazônia, em 1938, ocasião em que visitou Belterra, não tendo conhecido a Fordlândia, cujas plantações haviam sido abandonadas em 1934 (CORDEIRO, 2021, p. 147-149).

${ }^{11} \mathrm{Na}$ edição utilizada o texto é precedido de um significativo número de fotografias tiradas no decorrer da expedição (não creditadas), além da Planta do Rio Cuminá (faixa de fronteira com a Guyana Hollandeza nas cabeceiras dos rios Paru e Curipini (CRULS, 1973b, p. xv-xxx); na p. 12, Cruls indica em rodapé, o Major Luís Tomás Reis, como incumbido do serviço cinematográfico. FREIRE (2009) traz fotos da expedição reproduzidas a partir do Acervo Museu Histórico do Exército, creditadas a Benjamin Rondon.
} 
ressalta a imagem da decadência, que já se encontrava em A Amazônia misteriosa, ao assinalar a superioridade das inusitadas Amazonas em relação aos demais povos da floresta, e aqui resvalando fortemente para os ensinamentos positivistas em sua pontuação e escalonamento evolutivo dos povos em termos raciais. São inferiores, não civilizados, e a percepção do autor é, em primeira instância, civilizatória, avaliativa e julgadora do que vê, na perspectiva do que carrega como formação e compreensão do mundo.

[...] a maioria dos silvícolas que ainda vivem em terras brasileiras, e a respeito dos quais temos de vez em quando notícias e reproduções fotográficas, nada mais são do que um mísero rebutalho humano, de quase impossível confronto com a raça saída e forte que lhes foi origem[...]. (CRULS, 1973b, p. 87-88).

Para suas considerações sobre a decadência utiliza Alfred Wallace (1823-1913) partir de Travels on the Amazon and Rio Negro (Londres, 1895), destacando o excerto que segue, em sua contraposição ao anterior:

suas figuras são soberbas e diante das mais perfeitas estátuas eu nunca senti prazer igual ao que encontrava admirando esses modelos vivos de beleza a que podem atingir as formas humanas (CRULS, 1973b, p. 88).

Sem dúvida, olhares diferenciados. O distanciamento dos textos parece não corroborar as conclusões do autor, que encerra seus comentários elogiando Rondon e lamentando a diminuição crescente das populações indígenas ao longo do contato com a civilização que, já naquele momento, via como avassaladora com relação ao mundo natural ou ao mundo que a antecedia.

As dificuldades da viagem acompanham o caminho como um todo e parecem se avolumar conforme a "aventura" e a narrativa avançam. O desconforto cresce na mesma medida das distâncias percorridas, com acampamentos em lugares crescentemente precários, com pouca possibilidade de abrigo das intempéries, escassez de alimentos que aumenta a dependência com relação à caça e à pesca, além da falta de outros suplementos como remédios e, em especial, no caso específico do autor, o cigarro, a que não faltam referências e improvisos.

A 2 de dezembro Cruls registra a colocação do marco - I.F. (Inspeção de Fronteiras) no "descortino da serrania de Tumucumaque". Informa que, antes da "cintura de montanhas, avulta um pico granítico e escalvado, que pela sua configuração lembra o nosso Pão de Açúcar e assim vem sendo chamado, desde a primeira vez em que o vimos, faz alguns dias". Pão de Açúcar, que "levanta-se em pleno campo e fica situado muito antes da cordilheira. Está, portanto, em território brasileiro ..." (CRULS, 1973b, p. 121-122). Rondon decide fazer o seu "reconhecimento", em excursão realizada entre 05 e 06 de dezembro, descrita pelo autor como "nossa tormentosa excursão ao Pão de Açúcar", com caminhada que, prevista para metade de um dia, acabou por tomar um dia e meio. Da expedição retornaram "cansadíssimos e esfomeados" (CRULS, 1973b, p. 123-124). Nas palavras do autor,

\footnotetext{
De tal modo enganam as distâncias que o Pão de Açúcar nos parecia, então, a três ou quatro quilômetros, e eu e o meu companheiro seguimos na certeza de que, quando muito, ao meio-dia poderíamos estar de volta. Tanto assim que partimos inteiramente desprevenidos de qualquer provisão de boca e nem mesmo o seu cantil, que nunca o abandona, foi lembrado pelo Gertum. Não tardou, entretanto, que nos apercebêssemos de quanto era grande a nossa ilusão. Já havíamos andado umas boas duas horas e o Pão de Açúcar, sempre à nossa frente, ainda não mudara de aspecto e parecia tão longe como quando deixáramos o acampamento. (CRULS, 1973b, p. 124).
}

Mais duas horas de marcha para que se aproximassem da "falda do bloco de granito", em torno do qual, "baldadamente andamos à procura de qualquer nascente ou veio d'água que 
nos dessedentasse" - "já trazíamos a boca grossa e seca". Após encontrar uma pouca água entre folhas mortas e outros detritos orgânicos, provavelmente, sobra de alguma chuva, conseguiram refrescar os lábios para então fazer o que restava: "escalar o alcantil..." (CRULS, 1973b, p. 124). Chegaram ao alto do pico, "exaustos e banhados em suor" em torno das quatorze horas: "magnífico belvedere sobre a cordilheira que estadeava à nossa vista a sua extensa cadeia de montanhas" - na sua maior parte "fechada e portentosa floresta que se inicia ainda no plano, não longe da base do Pão de Açúcar e, logo a seguir, ganha os primeiros contrafortes e reveste todos os outros espigões" (CRULS, 1973b, p. 125).

Achavam-se na terra de fronteira (entre a linha de limites propriamente dita e outra que lhe corresse paralelamente a sessenta quilômetros de distância para dentro do território nacional), ou seja, tinham cumprido a missão programada.

O General decide por dar continuidade ao reconhecimento do local com alguns poucos homens, de modo que o restante da expedição - incluindo Cruls - inicia o retorno a Óbidos, depois de nova subida ao alto do Pão de Açúcar, ponto em que valoriza e realça, mais uma vez, o trabalho pesado dos homens que abriam o caminho:

10 de dezembro. - Eis-nos novamente sobre o Pão de Açúcar. Hoje, porém, bem mais fácil foi o seu acesso. Além de estarmos repousados, os carregadores, que subiram na frente, amarraram longas cordas em um ou outro ponto e, assim, não tivemos de andar continuamente a braços com os cardos e espinheiros-bravos. (CRULS, 1973b, p. 130).

Rondon levanta a bandeira nacional e, congratulando a todos pelo êxito da expedição, dá ao pico o nome Ricardo Franco. ${ }^{12}$ Encontravam-se a 687 quilômetros de Óbidos, nas seguintes coordenadas geográficas: Latitude $2^{\circ} 17^{\prime} 59^{\prime \prime}$ Norte e longitude $55^{\circ} 56^{\prime} 47^{\prime \prime}$ a Oeste de Greenwich (CRULS, 1973b, p. 135).

Expedição de que resultou, também, a ampliação do conhecimento da floresta, suas gentes, flora e fauna, com a coleta de materiais etnográficos - adornos, armas e utensílios recolhidos ao Museu Nacional, além do registro dos cerca de 200 quilômetros do território até então desconhecidos, as tomadas fotográficas de Benjamin Rondon, bem como as gravações cinematográficas do Major Thomaz Reis e, sem dúvida, os relatos e relatórios produzidos por Gastão Cruls, Cândido Mariano da Silva Rondon e Alberto José de Sampaio, chefe da Seção de botânica do Museu Nacional, que acompanhou a expedição, identificando e recolhendo várias espécies da flora local. Alguns artrópodes, então ainda desconhecidos, vieram a ser batizados por Cândido de Mello-Leitão com o nome de Cruls, associando crulsis à denominação, sendo um deles Sampaio e Cruls - Sampaiosia crulsi. (CORDEIRO, 2021, p. 113-114).

\section{AMBIVALENNCIAS DO OLHAR E DA ESCRITA}

Olhares que habitam, de longa data, o imaginário sobre a região. Olhares ambivalentes, lançados sobre a incomensurável dimensão da Amazônia, então ainda bem pouco conhecida e nunca visitada em sua inteireza por viajantes. Olhares aqui considerados para pensar o país/paisagem e a pátria/nação Brasil por entre intenções integradoras e apropriações que guardam forte relação com o pensamento positivista e ações autoritárias, mesmo quando bemintencionadas e resultantes de modelos civilizacionais conflitantes de ocupação e exploração, seja com relação ao potencial de sua natureza, seja com relação às populações locais, autóctones e migrantes.

\footnotetext{
${ }^{12}$ Homenagem a Ricardo Franco de Almeida Serra, capitão-engenheiro que teve participação importante na defesa do Forte Coimbra, em 1801, contra o ataque dos espanhóis (CRULS, 1973b, p. 131).
} 
Tordesilhas continua a ser marco que, de formas imaginárias e concretas, constitui linha que guarda permanência com relação à longa tradição de oposição das terras interiores e litorâneas no pensar o Brasil em seus inúmeros espaços, tornando-se visível ao longo da sua existência, com consistência especial e específica quando se tratou de pensar o país como nação nos meados do séculos XIX, avançando com cores diferenciadas ao longo do século XX e, nos alcançando, ainda agora, no século XXI - em especial se considerarmos a permanência de princípios que guardam relação com o positivismo e o autoritarismo, ainda hoje presentes em importantes parcelas de nós brasileiros.

$\mathrm{Na}$ memória a presença constante da viagem inaugural, não intencional, de Orellana que, em dado momento, viu-se fadado a prosseguir rumo ao desconhecido. Aos numerosos grupos indígenas com que teve contato e com quem, em boa parte, guerreou para a obtenção de alimentos - problema candente -, foi declarando tomar posse, de terras e homens, em nome de "Sua Majestade", navegando rumo ao desconhecido, em "viagem desesperada [onde] tudo tem sentido e nada o tem. $\mathrm{O}$ rio se alterna entre a esperança e a tragédia, entre milhas a serem computadas e o espaço da ignorância." (CICARONI, 1992, p. 27). Viagem e seu relato, que estiveram no horizonte de quantos se aventuraram na região, seja em busca do conhecimento ou de sonhados tesouros.

Significativa, também, a força dos textos de Euclides e Rangel na construção do "inferno verde" como imagem literária central para conferir relevo à natureza da natureza amazônica, ainda que com pouca ênfase, no conjunto dos seus escritos, para as populações indígenas. Leituras a que se somam as expedições de Rondon na propositura da sua integração para a conformação do Brasil em termos nacionais, tanto pela definição de fronteiras externas como pela diluição daquelas internas, na perspectiva de pensar a unidade na diversidade para a composição e forma do mosaico da nação em sua acepção ocidental. Nessa trajetória, entre outros autores que têm a região, ou mesmo, a nação por foco de reflexão e escrita, privilegiei Gastão Cruls, em seu projetar a imaginação e os aportes literários daquele momento, pela construção de cenas e personagens que transitam entre o real e o fantasioso, por vezes fantasmagórico, ainda que apoiado no conhecimento da época sobre a região em seu romance A Amazônia Misteriosa, ou do enfrentamento ao acompanhar os percalços e dificuldades que fizeram parte e marcaram a Expedição da Cordilheira do Tumucumaque, seguindo o rio Cuminá, conferindo visibilidade a uma Amazônia "sem excessos da palheta do artista", como já referido e assinalado no Prefácio de Roquette-Pinto à Amazônia que eu vi.

Nesse embate entre civilização e barbárie, ou da barbárie que entranha a civilização, Cruls, com mais alguns homens, iniciou o regresso em 14 de dezembro, em viagem também atribulada. No entanto, faziam agora o retorno, descendo e não subindo o rio. Merece atenção, por seu significado e sensibilidade, o final da narrativa, quando, ao avistar os pontos iluminados que possibilitaram identificar a cidade que foi o local de partida (13 de setembro de 1928) e era então, o de chegada (11 de janeiro de 1929) - após quatro meses de exploração de rios, gentes, matas e caminhos -, reavalia sua percepção do que fosse e representasse a cidade de Óbidos.

Quase às dezenove horas, já em águas do Amazonas, bate-me fortemente o coração, quando vejo, a certa distância, um pontilhado de luzes, que nascem à beira d'água e sobem tremulando pela encosta. É Óbidos, a cidade que ainda há quatro meses me parecia tão humilde e pequenina e agora avulta aos meus olhos como um grande centro de civilização (CRULS, 1973b, p. 160).

Mais uma vez a oposição com relação ao civilizado. Afirmação a que somo, para encerrar, a de Willi Bolle quando, em janeiro de 2007, percorreu o caminho da viagem de Orellana, de Quito a Macapá, ponto final de onde embarcou para Belém, delineando as expectativas acompanhadas e marcadas pela leitura do texto de Carvajal, de que carregava um exemplar. Ainda que tomando em conta as temporalidades diversas e as diferenças de 
navegação, ambos viajaram carregando a marca do desejo da exploração - do ver e sentir -, do conhecer, in loco, o que havia sido anteriormente acalentado. Ao final do percurso, a imagem que impressiona e permanece:

Quando no dia seguinte, tomamos o barco de Macapá para Belém, cruzamos o rio Amazonas em toda a sua largura. A imagem que se gravou em nossa memória é a do Rio-Mar indo ao encontro do Mar. (BOLLE, 2010, p. 29).

A primeira viagem, de Gastão Cruls, na convicção da oposição civilização/barbárie e na possibilidade da sua superação pelo processo civilizacional; a segunda, de Willi Bolle, resultando da proposta e esforço contemporâneo de convivência no mundo em termos planetários, para além das fronteiras nacionais, em perspectiva universal, de reconhecimento e convivência das diferenças em seus múltiplos saberes e modos de viver, que encontram sintonia com o que podemos ler no prefácio $O$ recado da mata, de Viveiros de Castro, ao livro A queda do céu, de Davi Kopenawa e Bruce Albert, perspectivando o processo contemporâneo de ataque à floresta e aos valores e modos de vida de sua população pela afirmação de que "temos a obrigação de levar absolutamente a sério o que dizem os índios pela voz de Davi Kopenawa", em termos da sobrevivência de todos os viventes (CASTRO, 2010, p. 15).

\section{REFERÊNCIAS}

BOLLE, Willi. A travessia pioneira da Amazônia (Francisco de Orellana, 1541-1542). In: BOLLE, Willi; CASTRO; Edna \& VEJMELKA, Marcel (org.). Amazônia: região universal e teatro do mundo. São Paulo: Globo, 2010. p. 19-56.

CARVAJAL, Frei Gaspar de. Relatório do novo descobrimento do famoso rio grande descoberto pelo capitão Francisco de Orellana. Introdução e notas de Guillermo Giucci. Trad. Adja Balbino Barbieri Durão; Introdução e notas. Maria Salete Bento Cicaroni. Edição bilingue. São Paulo: Scritta; Brasília: Consejeria de Educación de la Embajada de España, 1992.

CASTRO, E. Viveiros de. Prefácio - O recado da mata. In: KOPENAWA, Davi \& ALBERT, Bruce. [2010]. A queda do céu: palavras de um xamã yanomami. Trad. Beatriz PerroneMoisés. São Paulo: Companhia das Letras, 2015. p. 11-41.

CICARONI, M. Salete B. Viagens: história e literatura. In: CARVAJAL, Frei Gaspar de. Relatório do novo descobrimento do famoso rio grande descoberto pelo capitão Francisco de Orellana. Edição bilíngue. São Paulo: Scrita; Brasília: Consejeria de Educación de la Embajada de España, 1992. p. 9-28.

CORDEIRO, Matheus V. A Hiléia Amazônica em perspectiva: as impressões e leituras de Gastão Cruls sobre a Amazônia, a natureza e as sociedades indígenas (1925-1945). 2021. Dissertação (Mestrado em História das Ciências e da Saúde) - Casa de Oswaldo Cruz, FIOCRUZ, Rio de Janeiro, 2021.

CUNHA, Euclides da. Contrastes e confrontos. [Introdução de Olímpio de Souza Andrade; cotejo e estabelecimento do texto por Rolando Morel Pinto]. Cultrix; INL-MEC, 1975.

CUNHA, Euclides da. À margem da história. [Estabelecimento de texto e notas de Dermal de Camargo Monfrê]. Rio de Janeiro: Ed. Lello Brasileira, 1967. 
CUNHA, Euclides. Preâmbulo. In: RANGEL, Alberto. [1909]. Inferno verde (Scenas e Scenarios do Amazonas). $4^{\mathrm{a}}$ ed. Tours: Typographia Arrault \& Cia., 1927, p. 1-22.

CRULS, Gastão. A Amazônia misteriosa. Prefácio de Artur César Ferreira Reis. 9a ed. Rio de Janeiro: Livraria José Olympio Ed.; Brasília: INL/MEC, 1973a. Primeira edição: 1925.

CRULS, Gastão. A Amazônia que eu vi: Óbidos - Tumucumaque. Carta do General Rondon. Prefácio de Roquette-Pinto. $5^{\text {a }}$ ed. Rio de Janeiro: Livraria José Olympio Ed.; Brasília: INL/MEC, 1973b. Primeira edição: 1930.

CRULS, Gastão. Hileia Amazônica: aspectos da flora, fauna, arqueologia e etnografia indígenas. $3^{\mathrm{a}}$ ed., 48 reproduções de aquarelas de Hilda Veloso, Armando Pacheco e Georges Julien Simoni. Culs-de-lampe de Luís Jardim. Rio de Janeiro: Livraria José Olympio Ed., 1958. Primeira edição: 1944.

FREIRE, Carlos A. da R. Rondon: a construção do Brasil e a causa indígena. Brasília: Abravídeo, 2009.

GRIECO, Agrippino. O que é este romance segundo o crítico. In: CRULS, Gastão. A Amazônia misteriosa. $9^{a}$ ed. Rio de Janeiro: Livraria José Olympio Ed.; Brasília: INL/MEC, 1973a. $1^{\text {a }}$ orelha.

LISBOA, Karen M. Da expedição científica à ficcionalização da viagem: Martius e seu romance indianista sobre o Brasil. Revista do Arquivo Nacional, v. 21 N $^{\circ} 1$ Jan-Jun: A Corte no Brasil, v.21, n.1, p. 115-132, 2008. Disponível em:

http://hdl.handle.net/20.500.11959/brapci/107504. Acesso em: 19 abr. 2021.

NAXARA, Márcia R. Capelari. Cientificismo e sensibilidade romântica: em busca de um sentido explicativo para o Brasil no século XIX. Brasília: Ed.UnB, 2004.

PAIVA, Marco A. C. de. A ordem e a desordem da natureza: o sertão e a Amazônia em Gastão Cruls. Sociologias, Porto Alegre, ano 21, n. 51, maio-ago 2019, p. 242-277.

RANGEL, Alberto. [1909]. Inferno verde (Scenas e Scenarios do Amazonas). Prefácio de Euclydes da Cunha. $4^{\mathrm{a}}$ ed. Tours: Typographia Arrault \& Cia., 1927.

RANGEL, Alberto. [1913]. Sombras n’Água. Vida e paizagens no Brasil equatorial. Leipzig: F.A.Brockaus, 1913.

RONDON, Cândido M. S. Carta ao Dr. Gastão Cruls. La Victoria, 12 de São Paulo 84/150 (1º de junho de 1938). In: CRULS, Gastão. A Amazônia que eu vi: Óbidos - Tumucumaque. $5^{\text {a }}$ ed. Rio de Janeiro: Livraria José Olympio Ed.; Brasília: INL/MEC, 1973b, p. xxxii-xxxiii.

ROQUETTE-PINTO. Prefácio. In: CRULS, Gastão. A Amazônia que eu vi: Óbidos Tumucumaque. $5^{\mathrm{a}}$ ed. Rio de Janeiro: Livraria José Olympio Ed.; Brasília: INL/MEC, 1973b, p. xxxiv-xxxvi. 